\title{
DOM QUIXOTE NA AMÉRICA: CLAUDE LÉVI-STRAUSS E A ANTROPOLOGIA AMERICANISTA
}

Tradução de Estela Abreu

Há muito que os antropólogos deixaram de ser os especialistas da "sociedade primitiva" em geral, ou de sua suposta mentalidade. Desde que a antropologia começou a se profissionalizar e que a pesquisa de campo se tornou uma prática fundamental para a disciplina, todos os etnólogos são levados a se especializar no conhecimento de uma área geográfica ou de uma zona cultural específica, mesmo que seja para nela procurar invariantes de ordem bem geral. Essa especialização etnográfica, que se tornou necessária a partir das primeiras décadas do século XX pelo acúmulo de conhecimentos e pela exigência de exatidão própria do regime de especificidade da disciplina, tem incidências muitas vezes desconhecidas pelo grande público sobre as maneiras de pensar e de trabalhar do etnólogo. Dedicar-se ao estudo de sociedades ameríndias e não às sociedades africanas ou europeias é, primeiro, aderir a uma comunidade científica marcada por uma herança intelectual, um estilo de compromisso com seu objeto de estudo, preocupações teóricas e formas de interação profissionais que lhe são próprias; é, em seguida, familiarizar-se com particularidades culturais que vão alterar, muitas vezes até contra a vontade dos pesquisadores, as proposições teóricas mais abstratas.

Claude Lévi-Strauss é americanista, e basta ler Tristes trópicos - ou olhar as fotos de Saudades do Brasil - para compreender que seu encontro com os índios marcou profundamente sua sensibilidade e seu imaginário científicos, além de ter tido papel central na genealogia dos conceitos da antropologia estrutural. A contribuição de Claude Lévi-Strauss também transformou inteiramente a antropologia americanista, sobretudo a que trata do mundo amazônico: basta um exame superficial da literatura especializada para perceber de forma evidente que hoje "a etnologia indígena se escreve necessariamente a partir de Claude Lévi-Strauss, mesmo que seja debatendo com ele" (Viveiros de Castro, 2003).

No entanto, de todos os grandes antropólogos contemporâneos, Claude Lévi-Strauss é, sem dúvida, aquele cuja especialização regional parece, à primeira vista, a menos pertinente para a compreensão de sua obra. Como foi dito pelo próprio Lévi-Strauss, ele não se dedicou a outras pesquisas de campo 
depois de suas primeiras - e relativamente curtas - enquetes junto aos índios brasileiros; ao contrário de seus colegas que, em geral, começam a carreira redigindo uma longa monografia, Lévi-Strauss nunca escreveu um tratado sobre algum dos grupos encontrados, exceto o curto livro sobre a Família e vida social dos índios nambiquara (1948), publicado inicialmente como artigo no Journal de la Société des Américanistes; enfim, em suas primeiras obras teóricas - As estruturas elementares de parentesco, O pensamento selvagem -, as referências à etnografia americanista são bem discretas. Quanto às obras sobre a mitologia, tratam de maneira exclusiva de materiais ameríndios; mas, além de a titanesca empreitada das Mitológicas dar a impressão de iniciativa solitária, bastante afastada das questões que, na mesma época, preocupavam a maioria dos etnólogos americanistas, sobretudo fora da França, os enunciados indígenas explorados nesses livros são filtrados, após sua coleta no terreno, por tantas mediações que a relação com as sociedades produtoras desses relatos parece muito distante. Assim, o leitor pode ter a impressão de que a escolha que o autor fez por mitos indígenas - em vez de australianos, africanos ou siberianos - se deve mais a motivos contingentes que a motivos necessários. Em suma, Lévi-Strauss seria antropólogo por essência e americanista por acaso.

Se a dimensão americanista da identidade científica de Lévi-Strauss parece relativamente secundária, também é verdade que a influência do etnólogo sobre os estudos americanistas permaneceu limitada até os anos 1970. Com exceção da França, a literatura especializada produzida antes desse período não traz a marca de Lévi-Strauss; seus escritos são citados, mas na mesma medida em que seriam citados por etnólogos oceanistas ou africanistas, já que as referências feitas à sua obra remetem (exceto quanto à questão das organizações dualistas às quais nos referiremos mais adiante) a proposições teóricas mais gerais e não tanto às hipóteses referentes apenas às culturas ameríndias. A influência da antropologia de Lévi-Strauss sobre o americanismo, hoje reconhecida e célebre, ficou por muito tempo subterrânea quanto a seus efeitos e limitada quanto ao alcance. Assim, as discussões relativas às hipóteses da ecologia cultural norte-americana obscureceram, no interior da disciplina, as contribuições do estruturalismo durante todo o período de 1960 a 1975 . Como explicar esses fatos contraditórios? Como caracterizar o papel dos ameríndios na obra de Lévi-Strauss, a relação que esse universo cultural mantém com o projeto estruturalista, enfim, a posição singular que esse pensador ocupa no quadro da etnologia americanista? É para essas perguntas que este artigo deseja trazer elementos de resposta.

Americanista, Lévi-Strauss se tornou por acaso. Ele afirma isso várias vezes, tanto em Tristes trópicos, como nas entrevistas com Didier Eribon (De près et de loin [De perto e de longe]): um telefonema inesperado, uma decisão inopinada, e ei-lo a caminho do Brasil e dos índios. Acaso paradoxal, convém destacar, já que circunstâncias fortuitas levaram o mais teórico e inovador 
antropólogo do século XX a se instalar numa especialidade - o americanismo das terras baixas - que, de todas as etnologias regionais, era a mais arcaica tanto no plano das ideias como no do conhecimento etnográfico. De fato, na época em que Lévi-Strauss começou sua vida profissional e as pesquisas de campo, a antropologia mal se interessava pelos índios da Amazônia, pois era costume considerá-los mais deteriorados do que legítimos primitivos e, por isso, sem interesse científico dentro da perspectiva evolucionista. Além do mais, a antropologia culturalista que se desenvolvia então nos Estados Unidos sob a influência de Boas concentrava-se no estudo dos índios da América do Norte e da América Central; a ideia de ir trabalhar em grupos de cultura tão pobre como eram manifestamente os índios da Amazônia não tentava ninguém. Como lembra Charles Wagley, um dos pioneiros da etnografia amazônica, autor de uma monografia clássica sobre os tapirapé, os manuais universitários norte-americanos anteriores à Guerra mal mencionavam as populações das terras baixas da América do Sul, agrupadas sob a etiqueta Indians of the manioc area [índios da área da mandioca] (Wagley, 1979). O precioso material coletado nas décadas anteriores pelos pesquisadores e exploradores alemães - sobretudo Koch-Grunberg e von den Steinen - ainda era desconhecido ou de difícil acesso, e os raros trabalhos de etnologia voltados para essas culturas - no caso, os de Lowie e Métraux - se baseavam essencialmente em fontes históricas e em dados recolhidos por amadores, missionários, exploradores ou sertanistas. Enquanto os etnólogos especialistas da África, Ásia e Oceania já haviam produzido uma rica coleta de monografias hoje consideradas clássicas, não existia nenhuma obra marcante sobre as culturas indígenas das terras baixas da América do Sul. Aliás, apesar da contribuição de Lévi-Strauss, esse estado de conhecimento lacunar e de indigência analítica perdurou ainda por décadas, de acordo com a opinião acerba de Murdock em 1951 sobre a etnografia amazônica caracterizada, segundo ele, por "[...] a degree of inadequacy extreme even for South America" ["um grau de extrema inadequação até para a América do Sul"] (Murdock, 1951). Convém lembrar, enfim, que um reader americano publicado em 1976 tinha como subtítulo Ethnology of the least known continent [Etnologia do continente menos conhecido] (Lyon, 1974).

Por que, em tais condições, Lévi-Strauss permaneceu americanista, em vez de orientar suas pesquisas para áreas culturais mais documentadas, alimentando hipóteses teóricas mais dignas de atenção? O autor oferece vários elementos de resposta a essa pergunta, que ele mesmo se faz em De perto e de longe (1988: 83). Foi justamente, afirma ele, o lado "ciência do século XIX" (1988: 85) que o atraiu para tal especialidade. Nela, nada estava fixado, nem mesmo os quadros mais elementares do saber: o período e as modalidades da implantação humana no Continente, as grandes etapas da história pré-colombiana, a distribuição e a classificação das famílias linguísticas, as formas principais da organização social e, sobretudo, dos sistemas de parentesco - tudo precisava 
ser determinado. Entretanto, o aspecto retrô do americanismo não era decorrente apenas da qualidade do saber, mas também do estilo da prática científica, ainda próxima do que era no século anterior pela amplitude das expedições de descoberta, pela relativa indiferenciação que ainda reinava entre cientistas, exploradores (como Wavrin, Gheerbrandt, Flornoy e outros) e mateiros (como os sertanistas do Serviço de Proteção dos Índios), enfim pelo caráter mais extensivo que intensivo do trabalho de campo. Como mais um fator de atração para Lévi-Strauss, a história e a etnografia das culturas ameríndias das terras baixas da América do Sul estavam repletas de enigmas. Assim, a estreita coexistência, hoje, como no passado, de culturas ou de traços muito evoluídos e outros extraordinariamente primitivos era e continua de difícil explicação. Aliás, um exemplo concreto desse problema geral reteve durante muito tempo a atenção de Lévi-Strauss: era a famosa "anomalia jê" sobre a qual escreveu vários artigos (1944, 1958 [1952a, 1952b, 1956]), surgida do contraste perturbador entre, de um lado, o aspecto muito rudimentar da cultura material e do modo de vida dos grupos pertencentes à família linguística macro-jê e, por outro lado, a complexidade feérica de sua organização social e de sua vida cerimonial. Em matéria de enigmas, havia também muitos outros, visto que os dados que começavam a ser coletados - a respeito dos sistemas de parentesco, das relações intertribais e o papel da guerra nestas, das práticas rituais...- não correspondiam aos modelos interpretativos então dominantes na disciplina. A mitologia era, sem dúvida, o mais opaco desses mistérios americanos, pela estranheza radical de seus enunciados e pelo lugar central que ocupava na vida dos índios, sem que se conseguisse compreender a qual necessidade podiam corresponder tais relatos barrocamente absurdos. Já se sabe como Lévi-Strauss respondeu ao desafio intelectual que eles propunham. Além do arcaísmo do universo dos americanistas, o estado muito lacunar do saber sobre os índios e os sedutores problemas trazidos por suas culturas, Lévi-Strauss menciona ainda outro elemento que justifica seu apego pelas Américas e pelo americanismo: a natureza, as paisagens americanas e sobretudo a escala desmesurada que dá ao viajante a impressão de recuar no tempo. Tal imensidão remete a uma aurora do mundo em que a presença humana era rara e precária, e em que a temporalidade extensa dos deslocamentos no espaço acentua o exotismo das populações visitadas. Em suma, o americanismo oferecia a Lévi-Strauss um continente científico muito adaptado à sua sensibilidade e a seu modo de pensar, pelo estilo defasado, não moderno da pesquisa lá desenvolvida, pela margem importante que esse estado do saber deixava à imaginação e à especulação, propício à elaboração de hipóteses de grande porte, e enfim pela qualidade de alteridade que o jogo conjugado da natureza, história e ciência conferia às populações ameríndias. ${ }^{1}$

Convém constatar que um dos principais ingredientes desta "diferença perfeita", capaz de reter Lévi-Strauss nas Américas - e entre os americanistas -, foi sua relação peculiar com o tempo. Foi o lado antiquado de uma etnologia 
regional que encantou o estudioso, foi o mistério da história pré-colombiana que, direta ou indiretamente, alimentou muitos dos seus primeiros trabalhos; foi a temporalidade associada à grandiosidade da natureza americana que apresenta tão belas paisagens. Que o fascínio de Lévi-Strauss pelas Américas derive, sobretudo, de seu gosto pelas marcas da passagem do tempo pode parecer paradoxal, pois tanto se criticou o estruturalismo por sua atitude negativa em relação à história e sua suposta impermeabilidade à causalidade história. Porém, cada aspecto apontado pelo autor para justificar sua vocação americanista sublinha seu amor pelo que é antigo. Aliás, o próprio Lévi-Strauss destacou esse aspecto de sua personalidade intelectual ao evocar o que ele chamou de seu "quixotismo". Definiu essa característica, afastando-se do sentido habitual da expressão, como "o desejo obsessivo de encontrar o passado no presente" (1988: 134). Esse autodiagnóstico esclarece de modo surpreendente as reações de Lévi-Strauss aos diferentes grupos indígenas encontrados durante seu trabalho de campo no Brasil, tal como narra em seus textos.

Basta rememorar as sociedades evocadas em suas páginas mais célebres, aquelas sempre citadas pelo autor, como nota Fernanda Peixoto (1988: 96), cada vez que sua obra toma novo rumo. Há, primeiro, os Nambikwara, modelo da sociabilidade humana em estado nu, mas também náufragos da história, sobreviventes de um estado de civilização anterior impossível de ser pesquisado. Há os Bororo e os Caduveu, que perpetuam a lembrança de um passado glorioso, os primeiros pela riqueza e pela complexidade de sua vida ritual, os segundos pelo esplendor da ornamentação corporal, traços que já não correspondem a nada nas condições de existência em que Lévi-Strauss encontrou tais grupos. Há os Tupi-Kagwahib, últimos descendentes dos Tupinambá da costa, os canibais encontrados por Léry e Staden e imortalizados por Montagine; foi pelo prisma das crônicas do Renascimento que Lévi-Strauss evocou esses índios em Tristes trópicos. Há, por fim, as sociedades da costa noroeste americana de que ele tratou mais tarde. De fato, o gênio plástico dessas culturas - ao qual se agregam a qualidade e o prestígio das fontes que as citam a seu respeito (os relatos de Boas e Sapir) e o esplendor da natureza na qual elas vivem - basta para explicar a atração desses índios sobre Lévi-Strauss. Mas, neles, como nos Bororo, encontra-se o contraste tocante entre um estado contemporâneo de desamparo (convém não esquecer quais as condições de vida dos índios do Pacífico há 20 anos) e a magnificência de um estado passado ainda recente e ao mesmo tempo enigmático, pois esses artistas supremos, esses aristocratas magníficos que eram os índios da costa noroeste americana, eram, ao mesmo tempo, caçadores-coletores avessos a qualquer forma de agricultura.

Como se vê, as sociedades que mais fizeram vibrar a sensibilidade de Lévi-Strauss possuem, todas elas, certas características: a distância dolorosa entre um estado passado de riqueza cultural e uma condição presente de decadência e de abandono, forjada por uma história enigmática, entregue à 
contingência; ao mesmo tempo, a fidelidade obstinada à tradição, sintetizada numa prática ou num tipo de comportamento que resistem à mudança. Essa configuração é comum a muitas culturas ameríndias sobreviventes, mas algumas delas a encarnam aos olhos de Lévi-Strauss de modo exemplar: apresentam-se como uma transposição em chave sociológica dessa figura privilegiada da estética romântica que é a ruína. Esta reúne de fato os aspectos inerentes à atração exercida sobre Lévi-Strauss pelos Caduveu da América do Sul, ou pelos Kwakiutl da América do Norte: a ruína exibe a erosão pela história; reclama, para ser inteligível, um olhar que justaponha passado e presente, satisfaz, enfim, a imaginação, convidando-a a preencher os espaços vazios esculpidos pela passagem do tempo.

Ao contrário, quando falta esse distanciamento, quando o presente se oferece em tranquila plenitude ocultando a face do passado, a relação com a sociedade observada fica mal estabelecida. Prova disso é o episódio dos Mundé tal como Lévi-Strauss o descreve no capítulo XXXI de Tristes trópicos. Esse grupo, encontrado pelo autor quando ele ia ter com os Tupi-Kagwahib, tinha tudo para seduzir o etnólogo: era uma tribo desconhecida, que nunca tinha sido contatada e da qual não se sabia nada. Ora, "não existe perspectiva mais exaltante para o etnógrafo que a de ser o primeiro branco a entrar numa comunidade indígena", lembra Lévi-Strauss, destacando que se tratava de um privilégio já raro em 1938. No entanto, sua breve estada no território desses "graciosos indígenas... anfitriões pacientes e cordiais... de linguajar alegre... roçados abundantes..." deixa para o antropólogo "uma impressão de vazio"; ao "desejo obsessivo de encontrar o passado no presente", que empolga o autor, os Mundé contrapõem a barreira lisa de um presente sem falha aparente. Selvagens, esses índios são até demais; sem um passado que servisse de chave de leitura e do qual portariam as marcas, eles escapam ao desejo de inteligibilidade do observador. Isso pode ser percebido nas fotos publicadas em Saudades do Brasil: as dos Mundé são os mais neutros, os mais "profissionais" clichês de índios; aliás, poucos retratos deles e nenhuma foto que iguale em intensidade o olhar captado nos Bororo, o abandono dos corpos dos Nambikwara. Em resumo, falta a esses índios com aparência bem cuidada e feliz uma dimensão essencial, a que viria de indícios sobre outra condição de existência consumida pelo tempo.

Entre as cenas do passado reiteradas nos escritos de Lévi-Strauss como origem desse distanciamento temporal que confere às coisas e às culturas valor estético, há uma que tem, nessa obra, lugar privilegiado: a do "primeiro encontro" entre índios e europeus, no momento da descoberta do Novo Mundo. Esse quadro é uma espécie de "cena primal" da antropologia de Lévi-Strauss, por dois motivos estreitamente ligados. Primeiro, porque se trata de um encontro falho. Os europeus "ficaram surdos e cegos à diferença desse outro planeta" formado pelas Américas; em vez de ver, só reconheceram o que já lhes era familiar, como mostra Lévi-Strauss no capítulo de História de Lince, intitulado 
"Relendo Montaigne". Assim, invertendo a revisão histórica imaginada por Montaigne de uma descoberta dos índios pelos Antigos e não pelos espanhóis, o autor começa a adotar as vestes de um Léry, Staden ou Thévet para reviver, como se estivesse no lugar deles, o encontro com os tupinambá e corrigir o começo dessa história comum de percurso tão trágico. Ademais, a história da Descoberta vale como revelador privilegiado de um traço peculiar das culturas ameríndias das quais Lévi-Strauss não se cansou de indicar as manifestações ao longo de toda a sua obra, e que não cessou de reformular teoricamente. Convém lembrar as páginas admiráveis que dedica, em Tristes trópicos, às experiências de afogamento praticadas pelos índios antilhanos que buscavam determinar, testando a natureza de seus corpos, se os recém-chegados ibéricos eram humanos ou imortais de um gênero inédito, enquanto os europeus ainda deliberavam para saber se os índios eram humanos ou animais. O episódio ilustra de modo exemplar a "abertura para o Outro", uma curva especial dos mundos ameríndios ligada à maneira que os índios têm de se situar diante da alteridade. Essa característica foi desde cedo detectada por Lévi-Strauss, como mostram os dois artigos publicados em 1943. No primeiro deles, publicado em Renaissance com o título Guerre et commerce chez les Indiens de l'Amérique du Sud [Guerra e comércio entre os índios da América do Sul], ele estabelece o aspecto sociologicamente produtivo da guerra vista como forma de vínculo, transformando em relação positiva o que era até então considerado a negação de uma relação. No segundo, The social use of kinship terms among Brazilian Indians [O uso social dos termos de parentesco entre os índios brasileiros] (1943b), ele destaca a primazia da afinidade no universo social dos índios, a prioridade da relação com o não-idêntico sobre as ligações de consanguinidade ou, mais exatamente, de identidade. Tema que ele retoma sob outra forma na série de artigos sobre a organização dualista, nos quais mostra que os contornos particulares do dualismo americano não decorrem de uma forma primitiva de casamento, como se pensava até então, nem, como proporia Maybury-Lewis $(1979,1989)$, de uma simples propensão ao binarismo inerente ao exercício do pensamento em geral. Há, em todos esses fenômenos - o "clinâmen guerreiro" da sociologia indígena, o valor concedido à afinidade, a instabilidade das formas institucionais do dualismo e o ternarismo que as persegue - algo a mais, que Lévi-Strauss retomará ainda em várias aulas para compreender melhor (por exemplo, em État actuel des études Bororo [Estado atual dos estudos bororo] [ano 1972-1973], em Cannibalisme et travestissement rituel [Canibalismo e travestimento ritual] [ano 1974-1975]). Ele voltará a isso, sobretudo em Histoire de Lynx [História de Lince] (1991), a obra que encerra a imensa empreitada das Mitológicas. Nesse livro, ele apresentou a caracterização mais completa da "ideologia bipartite dos ameríndios" baseada num "dualismo em perpétuo desequilíbrio", ideologia que o autor opõe, por meio de uma longa meditação sobre Montaigne - o mais "aberto" europeu do Renascimento - à paixão do idêntico que caracteriza o pensamento ocidental. 
Americanista, Lévi-Strauss o foi, mas de modo essencial e não acidental. Ele o foi para além da razão teórica, no plano do imaginário científico, esse reservatório de adesões imediatas, no assunto de imagens, de lembranças de emoções no qual se enraízam as intuições e crenças íntimas a respeito do social, do cultural, do humano, antes que elas se traduzam em argumentação explícita. Assim, os índios ocupam em sua obra um lugar bem mais importante do que se poderia prever, pois a visão universalista de sua proposta é muito forte. O fascínio que exerce o mundo ameríndio - inclusive sua natureza e sua ciência - sobre o pensamento de Lévi-Strauss decorre de sua capacidade de satisfazer uma estética tomada pela "busca do passado no presente": preservadas da ocidentalização pelo isolamento e, ao mesmo tempo, desvalorizadas da relação consigo mesmas pela história, as sociedades indígenas do Brasil tornam-se, para Lévi-Strauss, a encarnação de uma alteridade ideal, aquela que por sua própria valorização da alteridade, acoplada a uma fidelidade heroica à tradição encarregada de desenvolver, desta ou daquela forma, a acolhida feita à preciosa diferença do Outro, aparece como a antítese absoluta do mundo Ocidental, obnubilado pelo desejo de mudança e desejoso de destruir tudo o que não se parece com ele. Nesse contraste que alimenta o pensamento de Lévi-Strauss, a relação com o tempo constitui tanto o eixo de oposição central entre o universo dos europeus e o dos índios, quanto a chave de leitura que permite decifrar as sociedades indígenas: é, de fato, no espaço entre o presente de um encontro mudo em si - a prova são os Mundé - e um passado ao qual ele possa ser referido, que aflora o trabalho da sensibilidade e do pensamento, que desperta a excepcional intuição etnográfica de Lévi-Strauss, levando-o a apreender, em um curto lapso de tempo, os contornos essenciais do estilo de uma cultura. ${ }^{2}$

A "indianização" do imaginário científico de Lévi-Strauss, impressa nas linhas de força que sustentam o corpo de suas ideias, tem efeitos sobre a teorização que ele propõe dos fatos de cultura e de sociedade, mesmo quando sua meta é o universal. Assim, parece claro que a teoria da aliança é, em parte, uma teoria ameríndia do casamento e, mais geralmente, do vínculo social, e que, para o pensamento de Lévi-Strauss sobre o parentesco, o peso dado à afinidade reflete uma inflexão particular da organização social indígena; que, enfim, O pensamento selvagem, os trabalhos de reflexão sobre o pensamento mítico, descrevem, sobretudo, o exercício do pensamento nas culturas animistas do norte e do sul das Américas. Isso não retira nada do aspecto inovador do estruturalismo de Lévi-Strauss, e menos ainda de seu interesse pelo conjunto da disciplina. Como lembrávamos no início deste artigo, todas as teorias gerais na antropologia têm origem em fatos culturais específicos, e esse enraizamento é mesmo a condição de seu interesse, a garantia de sua validade como hipóteses de âmbito universal. De fato, se despojadas desse apoio num terreno cultural necessariamente específico, as teorias de grande porte correriam o risco de ser 
apenas a máscara de nossas premissas culturais, que têm grande habilidade para se tornarem verdades universais.

Dito isso, o caráter tão poderoso quanto velado da inflexão americanista da obra de Lévi-Strauss contribui, sem dúvida, para explicar as particularidades da relação mantida por este antropólogo com a comunidade científica americanista. Essa relação se manteve por muito tempo no registro do mal-entendido. É preciso, primeiro, lembrar que depois dos artigos sobre o dualismo, dos quais o último foi publicado em 1956, Lévi-Strauss não fez mais análises técnicas sobre questões de sociologia ameríndia. ${ }^{3}$ Além disso, se a inspiração ameríndia foi forte na elaboração de As estruturas elementares do parentesco, já a etnografia das sociedades indígenas pouco aparece nessa obra. Tais fatos se explicam pelas pobrezas quantitativa e qualitativa do material disponível na época sobre a organização social dos grupos da Amazônia, em comparação com a literatura sobre a Austrália e o sudeste da Ásia. Além disso, sabe-se agora que a maioria dos sistemas dessa área vem de um tipo de sistema de parentesco que destaca o que Lévi-Strauss chamou de método das relações, em oposição à lógica de classes à qual fazem apelo os sistemas que fornecem a matéria principal de As estruturas elementares do parentesco. Isso explica porque as hipóteses inovadoras de Lévi-Strauss sobre a afinidade tardaram a enriquecer as pesquisas sobre o parentesco ameríndio. Foram necessárias várias décadas, e importantes remanejamentos da teoria estruturalista da aliança, sobretudo os realizados por L. Dumont, bem como sua aplicação inspirada por J. Overing às sociedades do conjunto das Guianas, para que os sistemas de parentesco amazônicos começassem a mostrar seus segredos.

Em resumo, a relativa raridade de referências explícitas às especificidades culturais do mundo ameríndio nas obras publicadas por Lévi-Strauss entre 1949 e 1964 (lançamento do primeiro tomo de Mitológicas) levou muitos especialistas a desconhecerem a contribuição inestimável do etnólogo francês aos estudos americanistas, e a não utilizarem as pistas de análise que ele havia aberto. Sem terem percebido as realidades culturais ameríndias escondidas por trás da apresentação universalista das propostas teóricas de Lévi-Strauss, e o proveito que delas poderiam tirar para melhor compreender os dados etnográficos aos quais eram confrontados, os especialistas se concentraram mais no método utilizado na obra de Lévi-Strauss do que nas intuições dele a respeito da natureza das sociedades indígenas. Desse ponto de vista, eles se colocavam no mesmo nível dos etnólogos africanistas ou oceanistas, embora o estado de sonolência teórica do americanismo até os anos 1970 e sua fraca abordagem dos fatos sociais tornassem essa etnologia regional sem dúvida menos apta que outras para absorver a contribuição do estruturalismo e fazê-lo frutificar. Era o avesso desse arcaísmo que encantava Lévi-Strauss nos estudos americanistas... Seja como for, esse método que se impõe à atenção dos especialistas é frequentemente mal compreendido. O nó do problema está na confusão entre 
identidade de método e identidade de objeto. Ocorre que os materiais etnográficos indígenas são "naturalmente" saturados de esquemas de oposições binárias, por motivos que decorrem da estrutura das ontologias indígenas. Por isso, destacar e descrever esses jogos de oposição não é necessariamente praticar o estruturalismo, e daí surge a polêmica entre Lévi-Strauss e Maybury-Lewis a respeito do dualismo (sobre o qual Lévi-Strauss voltará, aliás, para um acerto de contas em História de Lince) (1991: 311-315). Também nisso, a influência de Lévi-Strauss não é tratada corretamente: há os que parecem se servir de sua abordagem - ou contestá-la -, mas que apenas descrevem, deturpando-o, um elemento da realidade etnográfica ameríndia; ou, então, há debates sobre suas hipóteses sobre os jê, como fizeram os membros do Harvard Central Brazil Project, mas em um plano muito técnico e sem avaliar os desafios bem mais amplos que elas implicavam.

Só há 20 anos é que, definitivamente, os especialistas se deram conta da contribuição de Lévi-Strauss ao estudo das sociedades e das culturas ameríndias. No presente, paradoxalmente, a influência de Lévi-Strauss na etnologia americanista cresce dia a dia, ao mesmo tempo que conhece um certo - e sem dúvida provisório - eclipse em outros setores da disciplina. Prova disso é o lugar que todos os pesquisadores - sobretudo amazonistas - dedicam agora a suas hipóteses, as discussões que elas propiciam, a multiplicação de trabalhos de reflexão sobre Lévi-Strauss empreendidos por jovens especialistas, seja na França, seja no estrangeiro. Foi preciso, para que se percebesse a grande transformação trazida por Lévi-Strauss para a paisagem do americanismo, encontrar os meios teóricos de explicar as particularidades culturais de ordem muito geral, sem voltar a uma abordagem culturalista e permanecendo fiel à inspiração estruturalista; ou seja, encontrar os meios de expor com clareza as bases ameríndias do estruturalismo e mostrar seu interesse para o conjunto da disciplina. Foi o trabalho empreendido por Eduardo Viveiros de Castro e o grupo de brilhantes etnólogos formados no Brasil por esse pesquisador, retomando a caracterização e a teorização, sob o nome de "perspectivismo", dessa "abertura para o Outro" característica do pensamento ameríndio, e analisando como ela se traduz no "dualismo em perpétuo desequilíbrio" característico de suas formas de organização; é também o que buscam na França pesquisadores como Philippe Descola, procurando mostrar que as especificidades americanas do "pensamento selvagem" remetem a uma das modalidades de um esquema mais geral de identificação animista, ou Emmanuel Desveaux, empenhado em generalizar a aplicação do método estrutural restringindo-o à área americana; é ainda o que desenvolvem, a seu modo, americanistas britânicos como Joanna Overing ou Peter Gow, com suas análises refinadas da sociabilidade indígena ou do tratamento mítico da história. Logo, se a antropologia americanista, após décadas de mediocridade científica, tem hoje um lugar de vanguarda dentro da disciplina, se lhe é reconhecido agora um papel central no desenvolvimento 
teórico da antropologia geral, é porque, ao se mostrar fiel ao espírito e não à letra do estruturalismo, ela acabou por encontrar a obra de Lévi-Strauss para prossegui-la e fazê-la prosperar.

Artigo recebido para publicação em julho de 2011.

Anne-Christine Taylor é diretora do departamento de educação e pesquisa do Musée du quai Branly em Paris e diretora de estudos do Centre National de la Recherche Scientifique (CNRS). Publicou mais de sessenta artigos em revistas especializadas na área de antropologia. Seus temas atuais de pesquisa incluem, além da etnologia, os estudos de parentesco e da percepção histórica das populações indígenas, a área de museologia e arte. 


\section{NOTAS}

Este artigo foi originalmente publicado em Cahier de L'Herne: Lévi-Strauss, 2004, 82, p. 92-98. Agradecemos à autora e a Éditions de l'Herne, que gentilmente permitiram a reprodução do artigo em português (N. E.).

1 Convém especificar que esse planeta ameríndio que Lévi-Strauss tanto gosta de escrutar com sua luneta não inclui as "altas culturas" andinas e mesoamericanas, universo do qual o etnólogo nunca se aproximou, pois por vocação e por método se interessava, prioritariamente, pelas formas mais elementares da vida social e cultural.

2 A importância da questão da relação com o tempo na atração que Lévi-Strauss tinha pelo mundo ameríndio talvez ajude a explicar a intensidade das polêmicas que manteve não com os historiadores, mas com a ideologia da história que certas correntes historiográficas veiculam. A história era a paixão de Lévi-Strauss, mas - ele o repetiu muitas vezes não gostava das filosofias da história, e desconfiava muito do que lhe parecia, correta ou incorretamente, uma tentação de projetar a sombra do Sujeito histórico ocidental sobre essa agency que hoje se tenta restituir aos índios por meio de uma abordagem histórica mais respeitosa da capacidade de iniciativa das sociedades indígenas. Também não gostava da pretensão dos historiadores de explicar o próprio movimento do tempo, tanto mais porque o procedimento deles nesse domínio era exatamente o inverso do dele. Os historiadores são restauradores e não aqueles que contemplam as ruínas; longe de procurar o passado no presente, eles buscam pôr no presente o passado, a restituí-lo tal como era em suas cores primeiras.

3 Ele voltará, no entanto, a essa questão em algumas de suas aulas no Collège de France; ver Paroles données [Palauras dadas] (1984). 


\section{REFERÊNCIAS BIBLIOGRÁFICAS}

Lévi-Strauss, Claude. Guerre et commerce chez les Indiens d'Amerique du Sud. Renaissance, 1943a, 1, p. 122-139.

. The social use of kinship terms among Brazilian Indians. American Anthropologist, 1943b, 45, p. 398-409.

. Reciprocity and hierarchy. American Anthropologist, 1944, 46, p. 266-268.

. La notion d'archaisme en ethnologie. In: . Anthropologie structurale. Paris: Plon, [1952a] 1958, p. 113-132.

. Les structures sociales dans le Brésil central et oriental. In: . Anthropologie structurale. Paris: Plon, [1952b] 1958, p. 133-146.

. Les organisations dualistes existent-elles? In:

Anthropologie structurale. Paris: Plon, [1956] 1958, p. 147-180.

. Paroles données. Paris: Plon, 1984.

. Histoire de Lynx. Paris: Plon, 1991.

\& Éribon, Didier. De près et de loin. Paris: Plon, 1988.

Lyon, Patricia (org.). Native South Americans: ethnology of the least known continent. Boston/Toronto: Little, Brown and Company, 1974.

Maybury-Lewis, David (org.). Dialectical societies: the Ge and Bororo of Central Brazil. Cambridge, MA/Londres: Harvard University Press, 1979.

\& Almagor, Uri (orgs.). The attraction of opposites: thought and society in the dualistic mode. Ann Arbor: University of Michigan Press, 1989.

Murdock, George. Outline of South American cultum. New Haven: Human Relations Area Files, 1951.

Peixoto, Fernanda. Lévi-Strauss no Brasil: a formação do etnólogo. Mana, 1998, 4/1, p. 79-108.

Viveiros de Castro, Eduardo. Le mirage de la societé primitive. Le Nouvel Observateur, Hors-Série: Lévi-Strauss et La penseé sauvage, 2003, p. 44-45.

Wagley, Charles. Foreword. In: Maybury-Lewis, David (org.). Dialectical societies: the Ge and Bororo of Central Brazil. Cambridge, MA/Londres: Harvard University Press, 1979, p. IX-XIV. 
Resumo:

Em D. Quixote na América, Anne-Christine Taylor aborda o paradoxo da identidade americanista de Lévi-Strauss. O alcance geral e abstrato da obra de Lévi-Strauss e a pouca expressividade teórica e empírica do americanismo na época em que este realizou suas primeiras e curtas experiências de campo poderiam sugerir que a região onde o autor se formou enquanto antropólogo não teve influência sobre o desenvolvimento teórico de sua obra. A autora mostra, pelo contrário, que se americanista ele se tornou quase por acaso, a influência da experiência e do pensamento ameríndio sobre o estruturalismo de Lévi-Strauss foi tamanha que se pode falar em uma indianização do imaginário científico de Lévi-Strauss, mesmo quando sua meta é o universal.

\section{Abstract:}

In D. Quixote in America, Anne-Christine Taylor addresses the paradox of Lévi-Strauss' Americanist identity. The general and abstract range of Lévi-Strauss' work and the little theoretical and empirical expressivity of Americanism at the time of his first and short field experiences could suggest that the region where the author became an anthropologist had no influence on the theoretical development of his work. The paper shows, on the contrary, that if he became Americanist almost by chance, the influence of Amerindian experience and thought over the structuralism of Lévi-Strauss was such that one can speak of an "Indianization" of his scientific imaginary even when his goal is the universal.

\section{Palavras-chave:}

Lévi-Strauss; Americanismo; Antropologia americanista; História; Estruturalismo.

\section{Keywords:}

Lévi-Strauss; Americanism; Americanist anthropology; History; Structuralism. 